Aletheia

ISSN: $1853-3701$

publicaciones@fahce.unlp.edu.ar

Universidad Nacional de La Plata

Argentina

\title{
¿Dónde está Santiago Maldonado? Disputas por la memoria del pasado reciente en Argentina
}

\author{
Pighin, Daniela \\ ¿Dónde está Santiago Maldonado? Disputas por la memoria del pasado reciente en Argentina \\ Aletheia, vol. 10, núm. 19, 2019 \\ Universidad Nacional de La Plata, Argentina \\ DOI: https://doi.org/10.24215/18521606e030
}

Esta obra está bajo una Licencia Creative Commons Atribución-NoComercial-Compartirlgual 4.0 Internacional. 


\section{¿Dónde está Santiago Maldonado? Disputas por la memoria del pasado reciente en Argentina}

Where is Santiago Maldonado? Conflicts about the memory of the recent past in Argentina

Daniela Pighin

DOI: https://doi.org/10.24215/18521606e030

Universidad Nacional de General Sarmiento, Argentina

danielapighin19@gmail.com

Recepción: 12 Noviembre 2018

Aprobación: 21 Agosto 2019

Recepción: 12 Noviembre 2018

Aprobación: 21 Agosto 2019

\section{Resumen:}

Santiago Maldonado desapareció el $1^{\circ}$ de agosto de 2017 durante la represión que Gendarmería Nacional realizó en la localidad de Cushamen, en la provincia de Chubut, contra la protesta de la comunidad mapuche en la que Maldonado participaba. El sur argentino tiene una larga experiencia de reclamos del pueblo mapuche centrados en recuperar las tierras que consideran ancestrales, lograr la autonomía jurisdiccional y alcanzar el reconocimiento de libertad económico - productiva y de su identidad cultural. El $1^{\circ}$ de agosto de 2017, la Gendarmería ingresó al Pu Lof en Resistencia de Cushamen dado que el Movimiento Autónomo de Puel Mapu había cortado durante 24 horas la ruta 40, que recorre Argentina paralela a la cordillera de los Andes, para reclamar la liberación de su líder Facundo Jones Huala, detenido un mes antes en la provincia de Rio Negro. La Gendarmería Nacional había recibido orden de la justicia federal para despejar la ruta 40 pero, una vez que la cumplió, ingresó también a la comunidad de manera ilegal. La desaparición de Santiago Maldonado fue denunciada de forma inmediata por la comunidad, para luego, convertirse en el reclamo central de los organismos de Derechos Humanos y de diversas organizaciones políticas. Maldonado estuvo 78 días desaparecido hasta el hallazgo de su cadáver, sumergido en el Río Chubut, durante un rastrillaje que los buzos de la Prefectura realizaron, rio arriba respecto del lugar de la represión. La movilización social, política, jurídica y mediática que se produjo durante el tiempo que Maldonado estuvo desaparecido reflejó cómo la Historia Reciente argentina continúa abierta, se hizo evidente la presencia del pasado en el presente y las disputas sociales y políticas que de ello se desprenden. Más precisamente, quedaron expuestas las memorias en conflicto en torno a lo ocurrido durante la última Dictadura militar en Argentina y a la violación a los derechos humanos mediante la desaparición forzada y el Terrorismo de Estado. En este contexto, y entendiendo que los medios de comunicación son una herramienta clave donde se producen esas luchas por la memoria como proyección de discusiones y conflictos más profundos, el objetivo del presente trabajo radica en analizar cómo se presentó la desaparición y muerte de Santiago Maldonado en la prensa escrita argentina, ¿A qué imaginarios responde y qué significados tiene esa conceptualización?, ¿Qué luchas sobre el pasado reciente argentino visibilizó?, y ¿Qué posiciones se intentaron legitimar con su utilización pública?. Para dar respuesta a estos interrogantes se analizarán los diarios La Nación y Página 12 (versiones digitales) observando la existencia de una lucha por los sentidos del pasado que pugnó por el significado de la desaparición y de la muerte de Santiago Maldonado. Si bien se entiende que dichos periódicos no agotan las líneas de análisis del caso, se seleccionaron como punto de inicio de la investigación en tanto constituyen publicaciones masivas dirigidas a perfiles de lectores disimiles donde pueden rastrearse las disputas por la memoria antes mencionadas. El foco de análisis estará puesto en los meses de la desaparición y muerte de Santiago Maldonado para reflejar la existencia de una lucha por los sentidos del pasado que pugnó por atribuirle diferentes significados al destino del joven.

Palabras clave: Santiago Maldonado, Luchas por la memoria, Prensa escrita, Historia Reciente.

\section{Abstract:}

Santiago Maldonado disappeared on August 1, 2017, in Cushamen, Chubut, when the National Gendarmerie repressed the protest of the Mapuche community in which Maldonado participated. The Argentine south has a long experience of claims of the Mapuche people focused on recovering the lands they consider ancestral, achieving jurisdictional autonomy and the recognition of economic - productive freedom and their cultural identity. On August 1, the Gendarmerie entered the Pu Lof in Cushamen Resistance since the Puel Mapu Autonomous Movement had cut Route 40 for 24 hours to demand the release of its leader Facundo Jones Huala, arrested a month earlier in the province from Rio Negro. The National Gendarmerie had received an order from federal justice to clear Route 40, but once it was completed, it also entered the community illegally. The disappearance of Santiago Maldonado was reported immediately by the community, and then became the central complaint of Human Rights organizations 
and various political organizations. Maldonado was missing for 78 days until the discovery of his body, submerged in the Chubut River, during a search made by the divers of the Prefecture made, upstream with respect to the place of repression. The social, political, legal and media mobilization that occurred during the time that Maldonado was missing reflected how Argentina's Recent History remains open, the presence of the past in the present and the social and political disputes that arise from it became evident. More precisely, the contradictory positions on what happened during the last military dictatorship in Argentina and the violation of human rights through forced disappearance and state terrorism. In this context, and understanding that the media are a key tool in the struggles for memory, the objective of this work is to analyze the presentation of the disappearance and death of Santiago Maldonado in the Argentine newspapers. What meanings does that conceptualization have?, What conflicts about the recent Argentine past made visible?, and What positions were tried to legitimize with its public use ?. To answer these questions, the newspapers La Nación and Pagina 12 show the existence of conflicts over the senses of the past that fought for the meaning of the disappearance and death of Santiago Maldonado. These newspapers do not exhaust the lines of analysis of the case but constitute massive publications aimed at profiles of different readers where memory disputes can be traced. The focus of analysis will be on the months of the disappearance and death of Santiago Maldonado to reflect the existence of a struggle for the senses of the past that struggled to attribute different meanings to the fate of the young man.

KEYWORDS: Santiago Maldonado, Memory conflicts, Newspapers, Recent history.

Santiago Maldonado desapareció el $1^{\circ}$ de agosto de 2017 durante la represión que Gendarmería Nacional realizó en Cushamen, provincia de Chubut, contra una protesta de la comunidad mapuche. El sur argentino tiene una larga experiencia de reclamos indígenas centrados en recuperar las tierras que consideran ancestrales, lograr la autonomía jurisdiccional y alcanzar la libertad productiva y cultural ${ }^{1}$. El $1^{\circ}$ de agosto de 2017, la Gendarmería ingresó al Pu Lof en Resistencia de Cushamen dado que el Movimiento Autónomo de Puel Mapu había cortado durante 24 horas la ruta 40 para reclamar la liberación de su líder Facundo Jones Huala, detenido un mes antes. La Gendarmería Nacional había recibido orden de la justicia federal para despejar la ruta 40 pero, una vez que la cumplió, ingresó también a la comunidad de manera ilegal.

La desaparición de Santiago Maldonado durante la represión fue denunciada de forma inmediata por los habitantes del Pu Lof, para luego, convertirse en el reclamo central de los organismos de derechos humanos y de diversas organizaciones políticas. El joven estuvo 78 días desaparecido hasta el hallazgo de su cadáver en el Río Chubut, durante un rastrillaje que los buzos de la Prefectura realizaron, rio arriba respecto del lugar de la represión. La movilización social, política, jurídica y mediática que se produjo durante el tiempo que Maldonado estuvo desaparecido reflejó cómo la historia reciente argentina continúa abierta, se hizo evidente la presencia del pasado en el presente y las disputas sociales y políticas que de ello se desprenden. Más precisamente, quedaron expuestas las memorias en conflicto en torno a lo ocurrido durante la última Dictadura militar en Argentina.

En este contexto, y entendiendo que los medios de comunicación son una herramienta clave donde se producen esas luchas por la memoria, el objetivo del presente trabajo radica en analizar cómo se presentó la desaparición y muerte de Santiago Maldonado en la prensa escrita argentina, ¿A qué imaginarios responde y qué significados tiene esa conceptualización?, ¿Qué luchas sobre el pasado reciente argentino visibilizó?, y ¿Qué posiciones se intentaron legitimar con su utilización pública? Para dar respuesta a estos interrogantes se analizarán los diarios La Nación y Página 12 observando la existencia de una lucha por los sentidos del pasado que pugnó por el significado del caso Santiago Maldonado.

\section{LUCHAS POR LA MEMORIA EN LA PRENSA ESCRITA}

En los últimos años en Argentina se ha consolidado y expandido la historia reciente. Si bien no es una obligatoriedad epistemológica o metodológica, gran parte de las investigaciones de dicho campo se han asociado con el carácter traumático del pasado, vinculado al estudio del Terrorismo de Estado y de las violaciones a los derechos humanos. 
En ese contexto, los estudios sobre las memorias han cobrado protagonismo al evidenciar que, si bien el pasado es inmodificable, los sentidos sobre ese pasado no son fijos sino que están sujetos a variaciones y transformaciones de acuerdo a los intereses y preocupaciones del presente. Es decir que más allá de su veracidad, la memoria representa el pasado de quien recuerda siendo lo esencial el comprender qué contexto y procesos permitieron la construcción de ese recuerdo. De esta manera, la memoria se ve performada por marcos interpretativos sometidos a las trasformaciones de la sociedad que permiten la interacción entre diferentes niveles de tiempos y de sentidos. No se trata de pensar a los marcos sociales (Halbwachs, 2004 [1925]) como determinantes sino de comprender que "el pasado es una construcción cultural hecha en el presente, y por lo tanto sujeta a los avatares de los intereses presentes” (Jelín, 2002: 309).

De este modo, las percepciones sobre el pasado que la historia reciente coloca en el centro de sus indagaciones son el eje de disputas que buscan atribuirle sentidos a ese pasado. En el caso argentino, desde el retorno a la democracia, los modos de recordar los procesos violentos de los años ' 70 han evidenciado cómo las experiencias individuales entraron en relación y/o tensión con los discursos públicos esgrimidos desde diferentes "emprendedores de la memoria" (Jelín, 2002) y con la memoria hegemónica (Da Silva Catela, 2011). Es decir que coexisten miradas sobre la historia cercana que se enfrentan por sostener la verdad de lo vivido en la Dictadura y por otorgar los títulos de culpables e inocentes a distintos actores (Lvovich, Bisquert, 2008).

En este sentido, el presente trabajo analiza cómo las posiciones en torno a los conflictos mencionados se reflejan en los medios de comunicación. La complejidad de la historia reciente genera disputas no sólo dentro del campo historiográfico sino que tienen una fuerte presencia social. Los medios de comunicación son una herramienta clave donde se producen esas luchas por la memoria como proyección de discusiones y conflictos más profundos. De este modo, la creciente incorporación del pasado reciente en temas discutidos en los periódicos da cuenta de las disputas políticas en torno a la valoración de lo sucedido durante los años '70. Es decir que la cobertura del caso Maldonado funciona como marco de referencia para pensar qué implicancias pueden tener estas posiciones y permite abordar los modos en que en las denuncias y reclamos por la desaparición del joven incorporaron las discusiones en torno a las memorias del terrorismo de Estado.

Según Héctor Borrat (1989), los periódicos se constituyen como actores del sistema político que actúan sobre el ámbito de la influencia. Tienen una actuación pública destinada no solamente a informar sino a formar el presente, dado que lo convierten en tema de debate de la agenda pública, y a formar la mirada de sus lectores sobre ese presente. No se pretende trazar una línea directa y acrítica en el camino entre lo que el periódico comunica y la toma de posición del público pero es evidente que los diarios intervienen en dicho posicionamiento; permiten la construcción social de significados y se erigen como una trinchera de la memoria donde lo que se dice u omite y la forma en que se enuncia, permiten conformar visiones sobre la realidad.

En este contexto el presente trabajo pretende reponer el debate que se pudo leer en los diarios La Nación y Página 12 en torno al caso Santiago Maldonado. Más precisamente, cómo su desaparición y muerte fueron objeto de disputa en cuanto a los sentidos que se intentaron imponer, siendo esas significaciones un reflejo de las memorias sobre el pasado reciente en nuestro país. En este sentido, es válido destacar que la desaparición en Argentina presenta una carga política, jurídica y emocional particular: su asociación con los crímenes de lesa humanidad cometidos durante la última Dictadura. Si bien, antes del caso Maldonado existieron diversos casos de "gatillo fácil" e incluso desapariciones, esta situación reactivó las memorias sobre la figura icónica del desaparecido. Es decir, si bien para que un caso específico tome dimensiones públicas operan diversas variables, un punto esencial es el "proceso de desingularización (...) que implica que cada muerte remita a otras similares (...)” (Gayol, Kessler, 2018:21) y que en nuestro país refiere a 30 mil casos similares.

Otro eje a destacar, en cuánto a las particularidades de la desaparición y muerte de Santiago Maldonado, refieren al contexto nacional en que se produjo. Por un lado, se desarrollaba la campaña electoral para las elecciones legislativas. Más allá de los cargos que se elegían, existía una disputa real y simbólica sobre la 
conducción del poder político. Es decir que el Kirchnerismo, con la candidatura de la ex Presidente Cristina Fernández de Kirchner a Senadora Nacional dilucidaba frente a la alianza Cambiemos del actual Presidente Mauricio Macri qué sector político lideraba el poder, tanto en la práctica (se definía la mayoría parlamentaria) como en el plano de las representaciones (se trataba del retorno de Kirchner a la batalla electoral). En este contexto, las significaciones de la desaparición del joven se relacionaron con las estrategias de la campaña política, en la que los diarios analizados tomaron participación directa.

Por otro lado, desde la asunción de Cambiemos a fines de 2015, la política de derechos humanos ha sido relativizada desde el gobierno nacional creando un halo de desconfianza que la vincula a hechos de corrupción de la gestión previa. Dentro de esa deslegitimación, se han dado discusiones paradigmáticas que también influyeron en los modos en qué se interpretó el caso Maldonado. Diversos funcionarios del gobierno, e incluso el propio Presidente, han cuestionado públicamente la cifra de desaparecidos y el papel de los organismos de derechos humanos así como le han restado importancia a las fechas conmemorativas. El punto de inflexión de estos conflictos se produjo en mayo de 2017 a partir del beneficio del 2x1 con el que la Corte Suprema de Justicia habilitó la liberación del represor civil Luis Muiña. Dicho contexto funcionó como caldo de cultivo para evidenciar las disputas que existen acerca de cómo interpretar lo ocurrido durante la última Dictadura. En ese sentido, al analizar el impacto del caso Maldonado se debe tener en cuenta que la visibilidad que cobran determinados casos parte de "la interacción con la coyuntura política en la que se produce, a la forma en la que varios actores se involucran con ella, a su capacidad de remitir a otras muertes similares, y a su presencia en la agenda de los medios masivos de comunicación" (Gayol y Kessler, 2018:24).

En relación a la selección de las fuentes de análisis, se optó por referir a las publicaciones de los diarios La Nación y Página 12 en tanto se los considera ejes contrapuestos en torno a las memorias del pasado reciente, entendiendo que esas disputas intentarían ser zanjadas desde el caso Maldonado. Asimismo, si bien la repercusión social tuvo fuerte presencia en los medios televisivos y en las redes sociales, gran parte de la información que circulaba en dichos ámbitos tenían su baluarte en la agenda fijada por los periódicos aquí analizados.

A partir de lo mencionado anteriormente, el trabajo recorre la información publicada en los diarios entendiendo que la apropiación de la desaparición y muerte de Maldonado no se agota en la determinación de conocer qué y por qué sucedió sino en construir una cadena de significados que permitan legitimar diferentes interpretaciones sobre la historia reciente. Dichas memorias no constituyen únicamente una mirada sobre el pasado sino que habilitan procesos a aplicarse en el presente. De éste modo, el diario La Nación presenta una tendencia a analizar el caso Maldonado en términos que oculten o minimicen las responsabilidades sobre la Gendarmería y el gobierno nacional. Esta defensa del accionar represivo de las fuerzas de seguridad va de la mano con la reacciones del periódico respecto a los crímenes cometidos durante la Dictadura. Si bien, se reconoce el accionar violento e ilegal del Estado, se apela a cierta justificación (Di Marco, 2018). Esta posición puede asociarse con la "Teoría de los dos demonios" aunque, en ciertas ocasiones y sobre todo a través de las cartas de lectores, La Nación publica defensas a los crímenes cometidos en términos de una "Guerra Sucia" ${ }^{3}$. En este sentido, el diario defiende el intento de establecer la Ley de $2 \mathrm{X} 1$ para represores detenidos (De Vedia, 2018); cuestiona la continuidad de los juicios de lesa humanidad (Cappiello, 2018); deslegitima a los organismos de derechos humanos (Romero, 2017), vinculando sus políticas a las características negativas que atribuye al gobierno kirchnerista ("Los derechos humanos kirchneristas", 2016); y caratula de violentas a la comunidad mapuche y a las marchas por Maldonado, atribuyendo a la RAM (Tronfi, 2018), y a los movimientos políticos opositores acciones que justifican ser reprimidas ("Incidentes en Plaza de Mayo", 2017).

En cuanto al diario Página 12, el caso Maldonado es analizado con la matriz que vincula al gobierno de Mauricio Macri de manera directa con la Dictadura y que defiende las políticas de la memoria del kirchnerismo (Bruschtein, 12/8/2017). Presenta una continuidad entre las políticas económicas y represivas durante el Terrorismo de Estado y el actual gobierno (Rodriguez, 2018); revela el desinterés de 
Cambiemos por juzgar los crímenes cometidos durante la Dictadura (Pertot, 4/5/2017) y cierta tendencia al negacionismo (Valdés, 2016); dejando de manifiesto la mirada relativista del gobierno nacional sobre la política de derechos humanos ("Tratan de relativizar", 2016.4).

En relación a la estructura de análisis, el trabajo parte de la construcción de dos ejes temporales que permiten vislumbrar las posiciones de ambos periódicos. El primer apartado dará cuenta de cómo La Nación y Página 12 representaron la desaparición de Santiago Maldonado (entre los primeros días de agosto y el 17 de octubre) haciendo hincapié en cómo reflejan los hechos y a quiénes atribuyen las responsabilidades. El segundo eje se estructura en torno al hallazgo del cadáver en el Rio Chubut (el 17 de octubre) y la información derivada de la autopsia, cuyos resultados se publicaron el 24 de noviembre, teniendo en cuenta las interpretaciones de los diarios referidas a cómo se encontró el cadáver, cómo murió el joven y quiénes son los responsables.

\section{Primer eje: La desaparición de Santiago Maldonado}

$\mathrm{Al}$ analizar cómo ambos periódicos caracterizan la desaparición de Santiago Maldonado, se observa que el diario Página 12 alude constantemente al concepto de desaparición forzada. En la primera mención al caso se reproducen las declaraciones de la abogada Gómez Alcorta, defensora del lonko Facundo Jones Huala, quien refiere a una secuencia que el diario va a reproducir en reiteradas ocasiones:

Cuando entraron los gendarmes a los tiros todos salieron corriendo, entre ellos Santiago. Corrieron para un mismo lado para ocultarse entre la vegetación y hay quienes vieron dónde se ocultó Santiago. Pero entre los tiros y las agresiones, un segundo más tarde lo pierden de vista y escuchan que un gendarme da la voz de 'Tenemos uno' y luego acercan una camioneta de la Gendarmería, abren las puertas traseras y entre varios rodean las puertas para que no se pueda ver (Un desaparecido”, 2017)

De esta manera, la referencia al ingreso ilegal de la Gendarmería a Cushamen, la brutal represión contra la comunidad, el escape hacia el río Chubut, la golpiza y detención clandestina de Maldonado se convierten en el modo en que el diario presenta recurrentemente el caso.

En segundo lugar, Página 12 recurre habitualmente a citas de autoridad de los organismos de $\mathrm{DDHH}^{4}$ que reclaman la aparición del joven; así como a figuras del ámbito jurídico o político. A partir de ello, se teje una relación directa entre lo ocurrido con Maldonado y los 30 mil desaparecidos; y entre el gobierno nacional, la última Dictadura y los grandes grupos económicos. Dan cuenta de las mismas políticas para eliminar a quienes obstaculizan la implementación de un modelo de acumulación neoliberal. En relación a ello, por ejemplo, citan a Myriam Bregman, abogada en el juicio contra el genocida Etchecolatz, quien sostuvo que "Este gobierno prepara más represión, no podemos permitir que vuelvan a implementar la desaparición forzada de personas. Salgamos todos a la calle hasta que Santiago aparezca" (Meyer, 8/8/2017). En este mismo camino, puede analizarse la referencia a Adolfo Pérez Esquivel, activista de derechos humanos y querellante de la causa quien argumentó “(...) el Estado "es responsable directo", lo que agrava la situación de encubrimiento sobre esta desaparición forzada" ("Otro pedido", 2017). Cerca del primer mes de la desaparición de Maldonado, Página 12 publicó una nota que refiere al recorrido que víctimas del Terrorismo de Estado realizaron en el Museo de la Memoria. Además de mencionar sus reclamos por la aparición con vida del joven, también se alude a los mecanismos de desaparición llevados adelante por las Fuerzas Armadas en ese contexto (Forn, 2017). Es decir, que se afirman en el lector las relaciones entre el caso Maldonado y las desapariciones en Dictadura rememorando los modos en que estas se desarrollaban. Esta asociación toma especial fuerza dado que la desaparición del joven, respecto de otros casos de desaparición en democracia, tuvo la particularidad de ocurrir durante un despliegue de represión de las fuerzas de seguridad frente a la protesta social. Esto refuerza especialmente la comparación con la represión de la dictadura y la excepcionalidad del accionar de las fuerzas de seguridad, al ingresar a las tierras mapuches sin orden judicial. 
Como se mencionó anteriormente, Página 12 alude al vínculo de intereses entre el gobierno nacional, la justicia y los grandes grupos económicos. Esta relación impulsaría las acciones conjuntas del gobierno y la Gendarmería Nacional, para reprimir y disciplinar las manifestaciones que obstaculicen los objetivos de los sectores poderosos. A ello se sumaría la complicidad, el ocultamiento y la construcción de relatos por parte de los medios de comunicación leales a estos grupos. En relación a la justicia, el diario observa lentitud en los procesos, por ejemplo, porque no se tomó testimonio a los mapuches (Meyer, 18/8/2017) ni se realizaron peritajes en el lugar de la desaparición. Asimismo da cuenta de la admisión de Gendarmería como querellante de la causa por parte del Juez Otranto, a cargo del caso (Meyer, 18/8/2017).

Si bien el diario alude a una alianza represiva conformada por diversos actores de poder, la responsabilidad de la desaparición está más puntualmente dirigida a la Gendarmería Nacional y a la orden de represión emanada del Ministerio de Seguridad, dirigido por Patricia Bullrich, con la figura de su jefe de gabinete, Pablo Noceti. En relación a ello, publicó la ausencia de la Ministro a la cita con la Comisión de DDHH de la Cámara de Diputados para ofrecer detalles sobre cómo se procedía ante el caso ("Bullrich faltó", 2017) y remarcó el accionar de Bullrich en torno a la negación de la desaparición forzada ("El juez hasta ahora no ha catalogado la causa como desaparición forzada de personas"), la quita de responsabilidades al gobierno y a la Gendarmería ("No voy a hacer la injusticia de querer tirar un gendarme por la ventana") y la estigmatización de la comunidad mapuche (Bullrich buscó desarrollar un hecho de violencia cometido presuntamente por el grupo RAM") (Abrevaya, 2017). Asimismo, el periódico refiere a las responsabilidades vinculadas al Presidente Macri como la denuncia presentada por los representantes de la Liga Argentina por los Derechos del Hombre "por encubrimiento de desaparición forzada de personas" ("Una denuncia”, 2017); y las declaraciones de Raúl Zaffaroni, integrante de la Corte Interamericana de Derechos Humanos al comparar la reacción del Presidente con las del genocida Videla.

Finalmente, el diario se refiere a la complicidad de los medios de comunicación hegemónicos a partir de la difusión de un video por los canales de televisión 13 y TN donde se especula con la presencia de Maldonado en la provincia de Entre Rios ("La operación”, 2017), y a partir del papel del periodista de Canal 13 Jorge Lanata, quien desde su programa refirió a la existencia de la RAM y mostró ejemplos de sus armas y violencia. Según Página 12, "La simultaneidad de estas supuestas investigaciones periodísticas dejan la impresión de una maniobra de los organismos de inteligencia para encubrir violaciones a los derechos humanos, de la misma forma que lo hicieron durante la Dictadura" (“Con vida lo queremos”, 2017).

Si se analizan estas mismas variables en el diario La Nación, la presentación del caso toma un matiz visiblemente diferente. La primera mención fue publicada cinco días después de los hechos con el titular "Cristina Kirchner pidió la aparición con vida de Santiago Maldonado y responsabilizó a Gendarmería" ("Cristina Kirchner pidió”, 2017). De algún modo se pretende el desprestigio de la información dado que las hostilidades de los lectores hacia la ex Presidente podrían cargar con una connotación negativa, e incluso falaz, a la situación. Asimismo, la nota no refiere al contexto en que se produjo la desaparición de Maldonado, mencionando solo el lugar pero no la represión de las fuerzas de seguridad y poniendo el acento en la protesta mapuche. Es decir que se remarca la ilegitimidad de los reclamos indígenas que también queda de manifiesto al asociarlos con la figura de Jones Huala, caracterizado como líder de la RAM. En relación a ello, durante los primeros días de agosto en los que el diario no hizo alusión al caso Maldonado, sí realizó publicaciones que abonan esta conclusión. Por ejemplo, al referir a la destrucción de una estación del tren La Trochita apuntando a la RAM "cuyos folletos fueron encontrados entre los escombros y que hace menos de 10 días atacó a un puestero de la estancia de los Benetton" y al justificar el accionar de la gendarmería en tanto la tensión impulsada por la comunidad indígena "obligó esta mañana a personal de Gendarmería a despejar la Ruta Nacional 40 a la altura de Leleque” (Tronfi, 2017).

Los días posteriores se publicaron notas con similares objetivos. Por ejemplo, se historizó la violencia en Argentina en los años '70 donde se construye el paralelismo con los reclamos mapuches y con la RAM y se abona a la justificación de su represión al posicionarlos como foco de las responsabilidades ("La subversión", 
2017). En relación a ello, presenta las declaraciones de la Ministro Bullrich quien da cuenta de la falta de colaboración de la comunidad ("no pudimos entrar al territorio donde según ellos lo vieron por última vez"), de la familia Maldonado ("para eso necesitamos el ADN de algún familiar") y de la inocencia de las fuerzas de la Gendarmería ("la Gendarmería fue "investigada de pies a cabeza y todo dio negativo") ("Patricia Bullrich le pidió”, 2017). Asimismo, el diario construye una relación opuesta y violenta entre la comunidad mapuche y el resto de la sociedad ("La democracia abusada", 2017). La sección carta de lectores cobra un interesante valor en relación a cómo el diario le atribuye responsabilidades y contribuye a la estigmatización de los mapuches. De ese modo, se reproducen frases que alimentan la teoría de la creación de un Estado mapuche ("Que haya que respetar las identidades de los pueblos (...) no significa reconocer un Estado mapuche transcordillerano ilusorio y conflictivo". "Estados aborígenes", 2017); las características violentas de su accionar ("acciones vandálicas y delictivas de estas bandas". "Activismo", 2017); la relativización del caso Maldonado y su desaparición en el contexto represivo ("Pero más allá de Maldonado, desaparecen en la Argentina cientos (o quizás miles) de personas por año y nadie reclama". "Los que desaparecen", 2017); el desprestigio de los organismos de derechos humanos (“(....) el activismo de "DD.HH. SA" (busca) probar su desaparición a manos de la Gendarmería a cualquier precio y con la peor finalidad política concebible". "Santiago Maldonado", 2017); el apoyo al gobierno nacional ("El origen de los ataques que está recibiendo la ministra Bullrich ¿̇tendrá realmente que ver con la desaparición de Santiago Maldonad". "Críticas a la Ministra”, 2017) y la legitimación de las Fuerzas Armadas para actuar frente a ello (“(...) deben acudir sin demora y poner fin a cualquier grupo irregular que, en armas y desconociendo la ley, pretenda semejante atropello". "Insurgencia", 2017).

Finalmente, La Nación atribuye responsabilidades a los opositores políticos y apunta al desprestigio de los referentes en derechos humanos. En primer lugar, en pleno clima electoral, el diario alude a estrategias del Kirchnerismo para desprestigiar al gobierno de Cambiemos ("El caso Santiago Maldonado", 2017) y, al mismo tiempo, refieren a desapariciones ${ }^{5}$ o muertes violentas ${ }^{6}$ acontecidas durante las gestiones anteriores. En segundo lugar, acusa al Presidente del CELS y periodista de Página 12, Horacio Verbitsky, de colaborar con los crímenes cometidos durante la dictadura" (Álvarez Echazú, 2017), y a Hebe de Bonafini, Presidente de la Asociación Madres de Plaza de Mayo, de corrupción y desvío de fondos públicos recibidos para las políticas de defensa de los derechos humanos (Alconada Mon, 2017). Asimismo, algunas declaraciones y publicaciones de La Nación apuntan a un vínculo entre los organismos de derechos humanos y la oposición política. En este sentido, se publicaron las declaraciones del Ministro de Justicia y DDHH Germán Garavano quien sostuvo "(...) sabemos que algunos de ellos tuvieron y tienen mucha afinidad con la ex presidenta [Cristina Kirchner], esto los termina desprestigiando" ("Germán Garavano habló", 2017).

Las tensiones y puntos encontrados entre los diarios Página 12 y La Nación a la hora de reflejar la desaparición de Santiago Maldonado mantienen una línea de análisis similar durante todo el periodo. Durante el mes de septiembre e inicios de octubre, ambos periódicos refieren al menos a tres puntos de inflexión para continuar abordando el tema: la tensión en torno a tratar el caso Maldonado en las escuelas; la visualización de las marchas que reclaman por la aparición del joven (ocurridas al cumplirse el primer y segundo mes de la desaparición), y el proceso de apartamiento del juez Otranto, el primer magistrado a cargo del caso ${ }^{7}$. Si bien aquí no se abordan en profundidad, dichos procesos dotan a ambos periódicos de mayor tela sobre la que plasmar las proyecciones del caso que venían sosteniendo desde las primeras publicaciones.

A partir de lo analizado anteriormente se puede sostener que los medios de comunicación lucharon por significar la desaparición de Santiago Maldonado dado que la esencia de la información no radica solamente en revelar lo que sucedió con el joven sino en las relaciones entre memoria y olvido del pasado reciente; es decir en la toma de posición respecto al Terrorismo de Estado. La característica abierta con la que se identifica a la historia reciente es la que permite que las memorias no se cristalicen sino que posean un carácter transformador; es decir que no solo están sujetas a una construcción y elaboración sino también a la modificación vinculada a los procesos del presente. En este sentido, si bien las políticas de la memoria 
instaladas desde 2003 a partir de la búsqueda de juicio y castigo han tenido un fuerte anclaje social, son objeto de discusión frente a otras miradas que pretenden modificar dicha interpretación sobre el pasado. Estas memorias no han surgido de modo repentino, sino que están presentes desde el retorno a la democracia, pero desde la asunción de Cambiemos al gobierno nacional se han habilitado espacios para que cobren mayor autoridad. Las políticas de relativización y estigmatización de los DDHH han permeado el contexto para que dichas voces adquieran más fuerza. De este modo, se evidencia que la memoria no puede cancelarse en un solo sentido sino que permanece abierta a nuevas interpretaciones y luchas en las que los medios de comunicación participan de forma activa. Las miradas contrapuestas sobre el pasado reciente entre La Nación y Página 12 no surgen intempestivamente a partir del caso Maldonado sino que constituyen una disputa de larga data. Si bien no es uno de los objetivos de este trabajo, observar las publicaciones de los periódicos en torno a las conmemoraciones del 24 de marzo o la reapertura de los juicios a los represores permite una mirada más global para enmarcar ambas posiciones.

\section{SEgundo EJE: HALlazgo del CADÁver y RESUltados DE LA AUTOPSiA}

El martes 17 de octubre los medios de comunicación informaron sobre el hallazgo de un cadáver en el Río Chubut dentro de las tierras del $\mathrm{Pu}$ Lof. El cuerpo fue encontrado a partir de un nuevo rastrillaje autorizado por el Juez Lleral, 78 días después de la desaparición, y en un contexto políticamente revuelto en tanto transcurría la semana de cierre de campañas electorales para los comicios nacionales del domingo 22. Es decir, que se trataba de un proceso de más de dos meses, en pleno embate electoral, donde el destino incierto de Maldonado había permitido el debate sobre una actualidad intrínsecamente ligada al pasado traumático de nuestro país. En este sentido, por ejemplo, la existencia o no de responsabilidad de Gendarmería no sólo ofrecería pruebas para la resolución del caso sino elementos que permitirían justificar o continuar cuestionando el rol de las fuerzas de seguridad. Asimismo, las circunstancias que provocaron la muerte del joven, al margen de lo judicial, eran centrales para definir la credibilidad del Estado y de los organismos de DDHH. La comprobación o no de la desaparición forzada nutriría los argumentos para empoderarlos o deslegitimarlos.

El viernes 20 de octubre se realizó la autopsia sobre el cadáver. A partir del peritaje inicial se pudo confirmar que se trataba del cuerpo de Santiago Maldonado y que no presentaba heridas de bala ni signos de violencia. La familia lo reconoció a partir de los tatuajes, que estaban visibles dado que el proceso de putrefacción era incipiente y el cuerpo estaba en un buen estado de conservación, y a partir de la prueba de huellas dactilares. Posteriormente, se inició un proceso de análisis para determinar datos más precisos sobre su muerte. Debido a la complejidad de procedimientos, los resultados definitivos se publicaron el 24 de noviembre. En dicho informe se definió la muerte del joven como consecuencia del ingreso y permanencia en el agua helada. La hipotermia generó adormecimiento de los miembros y redujo la movilidad, que luego derivó en un desvanecimiento y en la sumersión. Asimismo, el cuerpo no tenía lesiones externas, ni de violencia ejercida por terceros.

Los diarios La Nación y Página 12 siguieron el proceso de hallazgo y de realización de la autopsia como escenario de lucha en torno a sus significados. De este modo, en relación al hallazgo del cadáver, Página 12 mantuvo un clima de sospechas y dudas al ratificar que si bien el rastrillaje contó con la presencia de veedores, estos no presenciaron el momento preciso del hallazgo, y al publicar las declaraciones del hermano de Santiago, Sergio Maldonado que encontraba "ilógico" el lugar donde se halló el cuerpo dado que ya había sido rastrillado en 3 oportunidades y por estar ubicado río arriba. A esto mismo apuntó el testimonio de Fernando Jones Huala, quien argumentó "Plantaron un cuerpo y lo hicieron mal (...) apareció mucho más arriba, en dirección norte, cuando el río desciende hacia el sur” (Meyer, 18/10/2017). Es decir que, a partir de la aparición del cadáver, Página 12 continuó poniendo en el eje de las responsabilidades a la Gendarmería Nacional y al gobierno de Mauricio Macri dejando abierto el escenario tanto para un asesinato como para 
la muerte por ahogamiento, en tanto ésta se habría producido cuando "un centenar de uniformados en armas (iban) contra ocho jóvenes desarmados que huyeron hacia el río” (Verbitsky, 2017). Para ello, recurre al material fotográfico y fílmico que se secuestró a Gendarmería, y que no había sido revisado durante las gestiones del juez Otranto, como evidencia de la presencia de Maldonado en el momento de la represión y del accionar de los gendarmes que ingresaron al Pu Lof y dispararon. Resulta interesante la duda que siembra el diario al afirmar que

Entre las 11.39 y las 11.40 , pueden observar al menos cinco gendarmes mirando con detenimiento hacia el río (...). ¿Qué estaban haciendo? ¿Qué observaban con tanta precisión? Un minuto después, a las 11.41, Echazú (Gendarme) sale del río, con su rostro ensangrentado y una escopeta antitumulto en la mano (Premici, 2017).

De esta manera, Página 12 tejió vínculos entre la Gendarmería, el gobierno nacional, la justicia y el Grupo Benetton. En primer lugar, porque los peritajes sobre las camionetas de Gendarmería se realizaron luego de ser lavadas "y que fue Noceti quien avisó a Gendarmería que se realizaría dicho peritaje” (Premici, 2017). En segundo lugar, porque voceros de la comunidad atribuyeron la complicidad de la empresa que tiene la posesión de las tierras (Spinetta, 2017). Y, en tercer lugar por las acciones que tomó el gobierno durante los 78 días de la desaparición, dando cuenta de cómo negaron la participación de Gendarmería y las órdenes ilegales de represión impulsadas por Noceti; pusieron en duda la presencia de Maldonado en el lugar; estigmatizaron a la comunidad mapuche; y desestimaron los reclamos por desaparición forzada.

Por su parte, el diario La Nación a partir de la aparición del cuerpo en el río Chubut, buscó generar un clima de sospechas en torno a la muerte de Maldonado, que corría de las responsabilidades al gobierno y la Gendarmería, y se vinculaba a la violencia mapuche y de los grupos opositores al Presidente Macri. Por un lado, el diario refiere los obstáculos que la comunidad mapuche interpuso ante el primer operativo de búsqueda argumentando que "(...) los mapuches prohibieron el ingreso al tratarse de un "lugar sagrado"” ("Caso Santiago Maldonado", 17/10/2017), y al mencionar que pusieron trabas a la justicia, por ejemplo, a través del Testigo E. Es decir, a partir de las declaraciones del joven que se encontraba junto a Maldonado al momento de cruzar el río y que argumentó ante la $\mathrm{APDH}^{8}$ ver que fue detenido por Gendarmería. El diario argumenta que dicho testigo nunca se ofreció a prestar declaración bajo juramento en el juzgado y que su relato "no se habría corroborado con la autopsia realizada sobre el cuerpo de Maldonado, que indicó que no tenía golpes” (Jastreblansky, 24/11/2017). Asimismo, La Nación alude a las declaraciones del Ministro Garavano sobre las declaraciones de los mapuches como entorpecimiento de la justicia ("Germán Garavano", 2017). Por otro lado, cuando para contextualizar el caso se alude a las circunstancias en que desapareció el joven, el periódico continúa poniendo el acento en la protesta y en la agresión mapuche a los gendarmes (Caso Maldonado”, 18/10/2017) ${ }^{9}$. En relación a ello, el diario refiere al uniformado Emmanuel Echazú que participó del operativo en el Pu Lof el día de la desaparición de Maldonado presentándolo como "el gendarme que había sufrido lesiones durante el operativo" y que "se presentó espontáneamente a los fines de ponerse a disposición de la investigación” "“Caso Maldonado”, 19/10/2017). Finalmente, el diario apunta con cuestionamientos al kirchnerismo sosteniendo que aprovechó la desaparición del joven para atribuir falsas culpas sobre el gobierno de Macri (Novaro, 2017). En esta posición se pueden enmarcar las referencias que La Nación realiza sobre las declaraciones de la diputada y referente de Cambiemos Elisa Carrió, quien atribuye responsabilidades al kirchnerismo al argumentar que “(...) esta verdad no involucra sólo al Estado. Esto es algo mucho más gordo, y el que sabe es un ex jefe de Seguridad: [Sergio] Berni" ("Elisa Carrió”, 2017). En este mismo sentido deben leerse las afirmaciones del diario en cuanto a la similitud del caso Maldonado y la muerte del Fiscal Nisman como maniobras para obtener beneficios políticos:

La muerte del fiscal se produce horas antes de una cita en el Senado donde iba a acusar a la ex presidenta de traición a la patria. El cuerpo de Maldonado aparece en el río Chubut días antes de unas elecciones legislativas en las que se juegan muchas cosas (Guyot, 2017). 
Siguiendo este mismo eje, el diario califica de violentas a las marchas realizadas en diferentes puntos del país, tras la confirmación de la identidad del cadáver (Palavecino, 2017), y recorre el caso Maldonado a través de fotografías emblemáticas, destacando entre ellas imágenes del cabildo de Buenos Aires pintado con frases contra el gobierno durante la primer marcha por la aparición del joven; el fuego provocado durante la marcha en la comisaría de Esquel; y la fotografía de un gendarme que ingresa a declarar al juzgado corriendo y cubriéndose el rostro ante agresiones ("En fotos", 2017).

Una vez publicados los resultados de la autopsia, hacia fines del mes de noviembre los diarios continuaron con la lógica desarrollada desde la aparición del cadáver. Por ejemplo, Página 12 si bien alude a los resultados científicos (Hauser y Kollmann, 2017), continúa poniendo la responsabilidad en la Gendarmería en tanto:

Maldonado pudo ser instado de modo irresistible, aterrado o empujado al agua lo que tipificaría alguna variante de homicidio (o) Los gendarmes, que estaban a metros del sitio en que se produjo el hallazgo macabro, lo vieron caer y no lo auxiliaron o hasta le impidieron recobrar la orilla. Podría tipificarse como abandono de persona o hasta como un asesinato similar al del pibe Ezequiel Demonty (Wainfeld, 2017).

Asimismo, para el diario, que Maldonado haya muerto ahogado "no quita la posible responsabilidad estatal en el hecho y en la cadena de obstáculos promovida desde el gobierno para dificultar llegar a la verdad" ("Tengo más dudas que antes”, 2017). En este sentido, hace alusión a los intentos del gobierno por estigmatizar a los mapuches y justificar la represión a través de la RAM. Según el diario, desde el Estado intentan construir la imagen de un enemigo interno argumentando que "los mapuches tendrían una vanguardia violenta, RAM (que) estaría vinculada a sectores mapuches violentos de Chile" y que sería apoyada por la oposición política para desgastar al Presidente (Granovsky, 2017). Finalmente, el diario alude a la responsabilidad de los medios de comunicación afines al gobierno de Mauricio Macri por la campaña de ocultamiento sobre el accionar de la gendarmería y del Estado (Bruschtein, 25/11/2017).

Una vez publicados los resultados de la autopsia, el cuerpo de Santiago Maldonado fue entregado a su familia para realizar su sepultura. Ese mismo día, fue asesinado el mapuche Rafael Nahuel en un operativo de represión y desalojo en Río Negro, provincia vecina a Chubut. Frente a ello, Página 12 argumentó que la represión fue realizada por las fuerzas de seguridad estatales y observó acciones similares al caso Maldonado en torno al silencio del gobierno y a la búsqueda de culpabilizar a la víctima. Para ello dio cuenta del comunicado emitido por el Ministerio de Seguridad donde se argumenta que la muerte se produjo por la pertenencia del joven a "una metodología de violencia armada, inadmisible con la democracia y el Estado de Derecho" (Pertot, 27/11/2017).

El proceso hasta aquí analizado por la matriz del diario Página 12 cobra características diferentes al rastrear el periódico La Nación. Por ejemplo, los resultados de la autopsia fueron postulados como prueba de la inocencia de la Gendarmería Nacional y del Estado en la muerte de Santiago Maldonado. De esta manera, es continua la alusión a la causa de muerte derivada del ahogamiento, sin precisar que se trataba de una situación enmarcada en un contexto de represión, y la referencia al valor científico de los datos derivados del estudio. Asimismo, se hace hincapié en que no existen en el cuerpo indicios de violencia (Jastreblansky, 24/11/2017) y se generan ciertas sospechas sobre la comunidad mapuche. Por un lado, al sostener que el Pu Lof donde fue encontrado el cadáver "nunca tuvo custodia judicial y fue monitoreado por la comunidad" (Jastreblansky, $25 / 11 / 2017)$. Por otro lado, al atribuir al mapuche que intentó cruzar el río con Maldonado el abandono del joven, sabiendo de sus dificultades para nadar y a pesar de que "el tatuador le manifestó su imposibilidad de continuar" (Jastreblansky,25/11/2017).

Esta mirada negativa a la comunidad se reafirma y profundiza a partir de las notas publicadas sobre el caso de Rafael Nahuel donde se prioriza la referencia a la violencia, el terrorismo y la actitud antidemocrática de los mapuches (Morales Solá, 2017). Estas afirmaciones le permiten construir una legitimación para el accionar de las fuerzas de seguridad dado que, a diferencia del caso Maldonado, frente a la muerte de Rafael Nahuel no existen dudas sobre la responsabilidad del Grupo Albatros. Es por eso que el diario califica al episodio como "Un virulento enfrentamiento con armas de fuego" (Gaffoglio, 2017) y ubica al joven mapuche dentro de 
un raid de violencia de larga data asociada a la RAM (Gaffoglio, 2017). La conceptualización que La Nación realiza a partir de la muerte de Rafael Nahuel coincide con la posición del Gobierno Nacional que califica al hecho como "enfrentamiento", "conflicto" o "escalada de violencia”, ratificado por la Ministra Bullrich quien sostuvo que resulta irrefutable la acción tomada por el grupo Albatros.

\section{CONSIDERACIONES FINALES}

Una determinada muerte puede exceder el ámbito singular de la vida familiar del fallecido, para movilizar procesos de fuerte repercusión social y política. De este modo, los significados que se construyeron en torno a la desaparición y muerte de Santiago Maldonado fueron disputados por grupos políticos y de DDHH, el Gobierno nacional, los medios de comunicación y la sociedad, consumidora de los diferentes significados que surgían en torno a ello. Dichas apropiaciones no tuvieron significaciones unívocas. La singularidad del caso activó lecturas que lo acercaban a los modos de pensar el pasado reciente y en particular la caracterización del accionar de las fuerzas de seguridad y el poder ejecutivo.

Desde 2003, y durante más de 10 años, las políticas de memoria, verdad y justicia trascendieron el frente de denuncia y resistencia de los organismos de DDHH y de los reclamos de ciertos sectores políticos, para transformarse en una política de Estado. Ello permitió la investigación y el juzgamiento de crímenes de lesa humanidad que continuaban impunes y el desarrollo de diferentes políticas públicas que interpretaban el accionar militar, en alianza con los grandes grupos económicos y con miembros del ala política y judicial. De esta manera, se impulsó una interpretación del pasado que buscaba el juicio y el castigo de los culpables y la heroización de quienes lucharon contra ese sistema.

Esta memoria sobre el pasado reciente tiene niveles altos de consenso social pero convive con interpretaciones distintas en torno a cómo pensar las responsabilidades de lo ocurrido en los años '70; es decir con memorias que exigen justicia para las víctimas de las guerrillas de los ' 70 y el perdón de los militares que actuaron bajo el cumplimiento de órdenes o que justifican el accionar de las Fuerzas Armadas durante la Dictadura, en términos de una guerra contra la subversión. Ello no sólo grafica una forma de interpretar el pasado sino que tiene incidencia real en el ámbito jurídico y en los modos de pensar las movilizaciones sociales y el accionar de las fuerzas de seguridad en nuestro país.

La memoria no solo nos permite pensar el pasado sino hacerlo en función de un futuro. En este sentido, que los diarios La Nación y Página 12 se enfrenten desde trincheras de la memoria da cuenta de su búsqueda por construir la hegemonía que cada uno considera válida. Desde su atrincheramiento apuntan a atacar y dañar las visiones del pasado que consideran enemigas de acuerdo a las verdades que pretenden erigir. De este modo, la lucha por significar la muerte de Santiago Maldonado es un ejemplo de una historia reciente cuyas representaciones están lejos de cerrarse en un solo sentido. Ese carácter inacabado es un conflicto intrínseco a su propia naturaleza e impide las posibilidades de construir sentidos compartidos al reactualizar continuamente el trauma de la violencia vivida en los años '70. Es dentro de esta sociedad que, tras la experiencia del Terrorismo de Estado ha desarrollado una sensibilidad particular ante la muerte, donde se observa el "valor de los cuerpos muertos (y de los cuerpos desaparecidos) como vehículos y símbolos políticos (...)" (Gayol, Kessler, 2018). No se pretende pensar el caso Maldonado solo como un pretexto para reactivar pugnas en torno a las memorias del terrorismo de Estado, sino como un hecho que hizo reemerger tales luchas, y la sensibilidad frente a las acciones de excepción a la legalidad, y que reactivó sentidos de rechazo, o aceptación, del Terrorismo de Estado.

\section{REFERENCIAS}

Abrevaya, S. (17 de agosto de 2017). Con muchas chicanas pero ninguna respuesta. Página 12. Recuperado de https: //www.pagina12.com.ar/57058-con-muchas-chicanas-pero-ninguna-respuesta 
Activismo mapuche. 27 de agosto de 2017. La Nación

Álvarez Echazú, M. (25 de agosto de 2017). Revelan nuevos datos sobre la relación de Verbitsky con la Dictadura. La Nación. Recuperado de https://www.lanacion.com.ar/politica/revelan-nuevos-datos-sobre-la-relacion-de-verbi tsky-y-la-dictadura-nid2056504

Alconada Mon, H. (27 de agosto de 2017). Citan a Bonafini por una apropiación millonaria. La Nación. Recuperado de https://www.lanacion.com.ar/politica/citan-a-bonafini-por-una-apropiacion-millonaria-nid2057006

Borrat, H. (1989). "El periódico, actor del sistema político" en Anàlisi:Quaderns de comunicació i cultura, No 12 , España.

Bruschtein, L. (25 de noviembre de 2017). Sin punto final. Página 12. Recuperado de https://www.pagina12.com.a r/78294-sin-punto-final

Bruschtein, L. (12 de agosto de 2017). Con vida lo queremos. Página 12. Recuperado de https:// www.pagina12.com.ar/56098-con-vida-lo-queremos

Bullrich faltó a la cita. (9 de agosto de 2017). Página 12. Recuperado de https://www.pagina12.com.ar/55459bullrich-falto-a-la-cita

Cappiello, H. (13 de julio de 2018). Un coctel de desidia, intereses políticos y reglas anticuadas. La Nación. Recuperado de https://www.lanacion.com.ar/politica/un-coctel-de-desidia-intereses-politicos-y-reglas-anticuadas-nid2152 752

Caso Santiago Maldonado: detalles y diferencias de los tres rastrillajes. (17 de octubre de 2017). La Nación. Recuperado de https://www.lanacion.com.ar/politica/detalles-y-diferencias-entre-los-tres-rastrillajes-del-caso-santiago-mal donado-nid2073041

Caso Maldonado: la fiscalía aclaró cuál es la situación del gendarme imputado. (19 de octubre de 2017). ). La Nación. Recuperado de https://www.lanacion.com.ar/politica/caso-maldonado-la-fiscalia-aclaro-cual-es-la-situacion-d el-gendarme-imputado-nid2073668

Caso Maldonado: resumen visual de una trama de angustia y misterio. (18 de octubre de 2017). La Nación. Recuperado de https://www.lanacion.com.ar/politica/caso-maldonado-78-dias-de-misterio-y-angustia-nid2073112

Críticas a la ministra. (30 de agosto de 2017). La Nación. Recuperado de https://www.lanacion.com.ar/opinion/delos-lectores-cartas-mails-nid2057837

Cristina Kirchner pidió la aparición con vida de Santiago Maldonado y responsabilizó a Gendarmería. ( 6 de agosto de 2017). La Nación. Recuperado de https://www.lanacion.com.ar/politica/cristina-kirchner-pidio-la-aparicion-c on-vida-de-santiago-maldonado-y-responsabilizo-a-gendarmeria-nid2050635

Da Silva Catela, L. (2011). "Pasados en conflicto. De memorias dominantes, subterráneas y denegadas". En: Bohoslavsky, Ernesto; Franco, Marina; Iglesias, Mariana y Lvovich, Daniel (comps.); Problemas de Historia Reciente del Cono Sur, Volumen I, Buenos Aires: Prometeo Libros/UNGS. Pp.99-124

De Vedia, M. (17 de enero de 2018). Tras el caso Timerman, militares detenidos piden un trato similar. La Nación. Recuperado de https://www.lanacion.com.ar/politica/tras-el-caso-timerman-militares-detenidos-piden-un-tra to-similar-nid2101297

Di Marco, L. (6 de abril de 2018). Un caso que quema y reabre las heridas de los años 70. La Nación. Recuperado de h ttps://www.lanacion.com.ar/opinion/un-caso-que-quema-y-reabre-las-heridas-de-los-anos-70-nid2123119

El caso Santiago Maldonado y su manipulación política. (30 de agosto de 2017). La Nación. Recuperado de https://w ww.lanacion.com.ar/opinion/el-caso-santiago-maldonado-y-su-manipulacion-politica-nid2057854

Elisa Carrió, tras el hallazgo en el río Chubut: Estoy consternada. (17 de octubre de 2017). La Nación. Recuperado de https://www.lanacion.com.ar/politica/elisa-carrio-tras-el-hallazgo-en-el-rio-chubut-estoy-consternada-nid2 073205

En fotos: todo lo que ocurrió durante los 78 días de la búsqueda de Santiago Maldonado. (21 de octubre de 2017). La Nación. Recuperado de https://www.lanacion.com.ar/politica/en-fotos-los-79-dias-de-la-desaparicion-de-santi ago-maldonado-nid2074413 
Estados aborígenes. (26 de agosto de 2017). La Nación. Recuperado de https://www.lanacion.com.ar/opinion/de-lo s-lectores-cartas-e-mails-nid2056733

Forn, J. (30 de agosto de 2017). Santiago Malonado y la visita de las Cinco en la Ex ESMA. Página 12. Recuperado de https://www.pagina12.com.ar/59729-santiago-maldonado-y-la-visita-de-las-cinco-en-la-ex-esma

Gaffoglio, L. (26 de noviembre de 2017). Un mapuche murió de un tiro en Villa Mascardi durante un enfrentamiento con Prefectura. La Nación. Recuperado de https://www.lanacion.com.ar/politica/un-mapuche-murio-de-un-ti ro-en-villa-mascardi-durante-un-enfrentamiento-con-prefectura-nid2085865

Gayol, S. y Kessler, G. (2018). Muertes que importan. Una mirada sociohistórica de casos que marcaron la Argentina reciente. Buenos Aires: Siglo XXI editores

Germán Garavano habló sobre Santiago Maldonado y pidió "no politizar un hecho tan desgraciado" (29 de agosto de 2017). La Nación. Recuperado de https://www.lanacion.com.ar/politica/german-garavano-nid2057596

Granovsky, M. (26 de noviembre de 2017). El estigma mata. Página 12. Recuperado de https://www.pagina12.com .ar/78521-el-estigma-mata

Guyor, H. (21 de octubre de 2017). Despreciamos los hechos y amamos las teorías. La Nación. Recuperado de https:/ /www.lanacion.com.ar/opinion/despreciamos-los-hechos-y-amamos-las-teorias-nid2074171

Halbwachs, M. (2004) [1925]. Los marcos sociales de la memoria. Barcelona: Anthropos Editorial.

Hauser, I. y Kollmann, R. (25 de noviembre de 2017). Una respuesta y nuevos interrogantes. Página 12. Recuperado de https://www.pagina12.com.ar/78298-una-respuesta-y-nuevos-interrogantes

Incidentes en Plaza de Mayo, tras la marcha por la aparición de Santiago Maldonado. (1 de septiembre de 2017). La Nación. Recuperado de https://www.lanacion.com.ar/politica/incidentes-en-plaza-de-mayo-tras-la-marcha-po r-la-aparicion-de-santiago-maldonado-nid2058935

Insurgencia. (28 de agosto de 2017). La Nación

Jastreblansky, M. (25 de noviembre de 2017). El caso continúa con la reconstrucción del hecho. La Nación. Recuperado de https://www.lanacion.com.ar/politica/el-caso-continua-con-la-reconstruccion-del-hecho-nid2085582

Jastreblansky, M. (24 de noviembre de 2017). Caso Maldonado: los peritos coinciden en que murió por "asfixia por sumersión" y que el cuerpo no estuvo en tierra. La Nación. Recuperado de https://www.lanacion.com.ar/politica/caso-maldonado-termino-la-junta-medica-conformada-para-establec er-como-y-por-que-murio-el-artesano-nid2085380

Jastreblansky, M. (24 de noviembre de 2017). Caso Santiago Maldonado. Quién es el testigo E y por qué no declaró ante la justicia. La Nación. Recuperado de https://www.lanacion.com.ar/politica/caso-santiago-maldonado-qu ien-es-el-testigo-e-y-por-que-no-declaro-ante-la-justicia-nid2075764

Jelín, E. (2002). Los trabajos de la memoria. Madrid: Siglo XXI editores

Jelín E. (2002). Las conmemoriaciones. Las disputas en las fechas infelices. Madrid: Siglo XXI editores

La subversión de la historia. (7 de agosto de 2017). La Nación. Recuperado de https://www.lanacion.com.ar/opinio n/la-subversion-de-la-historia-nid2050627

La operación del video. (11 de agosto de 2017). Página 12. Recuperado de https://www.pagina12.com.ar/55873-laoperacion-del-video

Los derechos humanos kirchneristas. (3 de abril de 2018). La Nación. Recuperado de https://www.lanacion.com.ar/ opinion/los-derechos-humanos-kirchneristas-nid1885640

Los que desaparecen. (31 de agosto de 2017). La Nación. Recuperado de https://www.lanacion.com.ar/opinion/delos-lectores-cartas-mails-nid2058158

Lvovich, D. y Bisquert, J. (2008). La cambiante memoria de la dictadura. Discursos sociales y legitimidad democrática. Buenos Aires: UNGS.

Meyer, A. (18 de octubre de 2017). "El cuerpo fue plantado". Página 12. Recuperado de https://www.pagina12.com .ar/69967-el-cuerpo-fue-plantado

Meyer, A. (8 de agosto de 2017). "Pretenden lavarse las manos”. Página 12. Recuperado de https://www.pagina12.c om.ar/55185-pretenden-lavarse-las-manos 
Meyer, A. (18 de agosto de 2017). Una parte interesada. Página 12. Recuperado de https://www.pagina12.com.ar/5 7314-una-parte-interesada

Morales Sola, J. (26 de noviembre de 2017). Un grupo minoritario que desafía al Estado argentino. La Nación. Recuperado de https://www.lanacion.com.ar/politica/un-grupo-minoritario-que-desafia-al-estado-argentinonid2086664

Novaro, M. (19 de octubre de 2017). Se abre el camino a la verdad. La Nación. Recuperado de https://www.lanacion .com.ar/opinion/se-abre-el-camino-a-la-verdad-nid2073442

Otro pedido de renuncia para Bullrich. (29 de agosto de 2017). Página 12. Recuperado de https://www.pagina12.co m.ar/59555-otro-pedido-de-renuncia-para-bullrich

Palavecino, D. (21 de octubre de 2017). Caso Maldonado: manifestantes atacaron y quemaron la sede del gobierno de Mar del Plata. La Nación. Recuperado de https://www.lanacion.com.ar/politica/caso-maldonado-manifestant es-atacaron-y-quemaron-la-sede-del-gobierno-de-mar-del-plata-nid2074374

Patricia Bullrich le pidió a la resistencia ancestral mapuche que se abra y ayude en la búsqueda de Maldonado. (12 de agosto de 2017). La Nación. Recuperado de https://www.lanacion.com.ar/politica/patricia-bullrich-le-pidio-ala-resistencia-ancestral-mapuche-que-se-abra-y-ayude-en-la-busqueda-de-santiago-maldonado-nid2052495

Pertot, W. (27 de noviembre de 2017). Con la idea fija en el enemigo interno. Página 12. Recuperado de https://ww w.pagina12.com.ar/78696-con-la-idea-fija-del-enemigo-interno

Pertot, W. (4 de mayo de 2017). Apoyo oficial para el fallo. Página 12. Recuperado de https://www.pagina12.com.a r/35533-apoyo-oficial-para-el-fallo

Premici, S. (19 de octubre de 2017). Foto a foto. La represión de la Gendarmería. Página 12. Recuperado de https:// www.pagina12.com.ar/70132-foto-a-foto-la-represion-de-la-gendarmeria

Rodriguez, C. (25 de marzo de 2018).Un atropello de los derechos básicos. Página 12. Recuperado de https://www. pagina12.com.ar/103815-un-atropello-de-los-derechos-basicos

Romero, L. (20 de abril de 2017). El discurso intolerante de los organismos de derechos humanos. La Nación. Recuperado de https://www.lanacion.com.ar/opinion/el-discurso-intolerante-de-los-organismos-de-derechoshumanos-nid2013475

La democracia abusada. (13 de agosto de 2017). La Nación. Recuperado de https://www.lanacion.com.ar/opinion/l a-democracia-abusada-nid2052583

Santiago Maldonado. (29 de agosto de 2017). La Nación

Spinetta, F. (20 de octubre de 2017). Fernando Jones Huala. Página 12. Recuperado de https://www.pagina12.com .ar/70379-fernando-jones-huala

Tengo más dudas que antes. (25 de noviembre de 2017). Página 12. Recuperado de https://www.pagina12.com.ar/ 78299-tengo-mas-dudas-que-antes

Tratan de relativizar los crímenes. (11 de noviembre de 2016). Página 12. Recuperado de https://www.pagina12.co m.ar/2415-tratan-de-relativizar-los-crimenes

Tronfi, A. (2 de agosto de 2017). Chubut: incendian una emblemática estación de La Trochita. La Nación. Recuperado de https://www.lanacion.com.ar/sociedad/chubut-incendian-una-emblematica-estacion-de-la-tro chita-nid2049284

Tronfi, A. (23 de junio de 2018). Tiraron una torre repetidora de la TV Pública en Esquel: sospechan de la RAM. La Nación. Recuperado de https://www.lanacion.com.ar/sociedad/tiraron-una-torre-repetidora-de-la-tv-publi ca-en-esquel-sospechan-de-la-ram-nid2146847

Un desaparecido tras la represión en Cushamen. (3 de agosto de 2017). Página 12. Recuperado de https://www.pagi na12.com.ar/54190-un-desaparecido-tras-la-represion-en-cushamen

Una denuncia contra Macri. (30 de agosto de 2017). Página 12. Recuperado de https://www.pagina12.com.ar/5975 7-una-denuncia-contra-macri

Valdés, J. (15 de agosto de 2016). Contra el negacionismo del Estado. Página 12. Recuperado de https:// www.pagina12.com.ar/diario/elpais/1-306894-2016-08-15.html 
Verbitsky, H. (18 de octubre de 2017). La última foto de Santiago Maldonado. Página 12. Recuperado de https://w ww.pagina12.com.ar/69887-la-ultima-foto-de-santiago-maldonado

Wainfeld, M. (26 de noviembre de 2017). El cuerpo en el río. Página 12. Recuperado de https://www.pagina12.com .ar/78508-el-cuerpo-en-el-rio

\section{Notas}

1 Para un análisis en profundidad se puede consultar Kropff, L. (2005). Activismo mapuche en Argentina: trayectoria histórica y nuevas propuestas. CLACSO http://bibliotecavirtual.clacso.org.ar/clacso/gt/20101026125925/6Kropff.p df

2 Concepción que equipara la violencia de las FFAA durante el Terrorismo de Estado a la de las organizaciones guerrilleras que actuaron en ese contexto

3 Concepción propia de las FFAA para legitimar la aplicación del Terrorismo de Estado (4) "En los últimos meses hemos advertido intentos por negar el genocidio, reinstalar 'la teoría de los dos demonios' y desprestigiar la lucha de los organismos de derechos humanos".

4 Asociaciones Madres y Abuelas de Plaza de Mayo, HIJOS (Hijos e Hijas por la identidad, la justicia contra el olvido y el silencio). CELS (Centro de estudios legales y sociales). EMJV (Encuentro memoria, verdad y justicia). CPM (Comisión provincial por la memoria)

5 Julio López e Iván Torres

6 Tragedia de Once, ocurrida el 22 de febrero de 2012, que causó 55 muertos

7 El Juez Guido Otranto fue separado de la causa el 22 de septiembre por haber prejuzgado el caso en declaraciones periodísticas. En su reemplazo fue designado el Juez Gustavo Lleral.

8 Asamblea Permanente por los Derechos Humanos (10) "El 1 de agosto, cerca de las 11.15, efectivos de Gendarmería avanzaron sobre un corte en la ruta 40 en Chubut. Al ser agredidos por los manifestantes, ingresaron al predio que ocupa la comunidad mapuche Pu Lof de Resistencia en la estancia Leleque, en Chubut".

9 "El 1 de agosto, cerca de las 11.15, efectivos de Gendarmería avanzaron sobre un corte en la ruta 40 en Chubut. Al ser agredidos por los manifestantes, ingresaron al predio que ocupa la comunidad mapuche Pu Lof de Resistencia en la estancia Leleque, en Chubut".

\section{BY-NC-SA}

